\title{
Contraceptive practice and unplanned pregnancy among single university students
}

\author{
J B COLE, F C L BEIGHTON, IVOR H JONES
}

British Medical fournal, 1975, 4, 217-219

\section{Method}

Data were obtained by asking three samples of unmarried women students attending the student health service to participate in a confidential structured interview. Of the 338 women approached two refused. We used a standard interview format, dealing with university achievements, family background (including religion, social class, and parental attitudes to contraception), sexual experience, and attitudes towards the various methods of contraception.

The three samples were obtained as follows: the pregnancy group consisted of 51 women attending consecutively for pregnancy diagnosis, usually with six to eight weeks' amenorrhoea; the contraceptive group consisted of 104 women attending the contraceptive clinic. They were interviewed on an interval basis. One clinic attender conceived during the survey and was therefore included in the pregnancy group; the third group was a random sample of 181 women attending for general medical attention. They were taken from those attending on all weekdays, both morning and afternoon sessions. This group was composed of 113 women who stated that they had had sexual intercourse and 68 who said they had not. Both refusals occurred in this group. There were two interviewers. The pregnancy and contraceptive groups were both seen by a male doctor and the random sample by a female interviewer. As the interviewers saw separate groups it was not possible to test for interviewer effects.

Analysis-Most of the data were categorical in type; hence the $\chi^{2}$ test was used to test the degree of association between variables. The large number of cross-tabulations necessitated setting the level of significance at 0.01 or beyond.

\section{Results}

The subjects were aged 17-28 years with a modal age of 19 years, the same mode as the female university population. Faculty representation, social class of father, and domicile did not differ significantly from that of the university population.

\section{SEXUAL LIFE AMONG UNIVERSITY STUDENTS}

Among the random sample $15 \%$ had had intercourse by the age of 16 , and the remainder was almost equally divided between those beginning between 17 and 18 years and those beginning when they were 19 years or more. Most $(60 \%)$ of the sexually experienced reported the menarche between 13 and 15 years.

Intercourse usually occurred within a stable monogamous relationship. Over a third $(37 \%)$ of these women had sustained such a relationship for a year or more. Though $22 \%$ of the sexually experienced women did not have a steady sexual partner at the time of the survey, only two women were maintaining sexual relationships with more than one man simultaneously. A small majority $(53 \%)$ of these women had had intercourse with only one man. This pattern suggested that serial monogamy was the usual form of relationship. When a stable relationship ceased heterosexual activity stopped or occurred only occasionally until a new "steady" relationship had developed, so sexual activity was often episodic.

\section{FACTORS INFLUENCING THE START OF SEXUAL LIFE}

Women were divided into those who had begun heterosexual activity (268) and those who had not (68). The factors differentiating

Department of Psychiatry, University of Melbourne, Victoria, Australia

IVOR H JONES, MD, MRCP, consultant psychiatrist 
the two groups were age, religiosity, domicile, and those relating to the male partner. The most important single factor associated with the start of heterosexual activity was increasing age. Of those over 21 years in the random sample $95 \%$ had had intercourse.

There were three measures of religiosity: denomination, whether the upbringing had been religious, and current religious devotion. So few women belonged to denominations other than Roman Catholic or Protestant that they were excluded from cross-tabulations of denomination. Those with a religious upbringing and a strong religious devotion $(22 \%)$ were least likely to have begun heterosexual activity. Since those with strong religious devotion were more likely to be Roman Catholic a significantly higher proportion of the virgins were of this denomination.

There was a significant difference in domicile between the virgins and the sexually experienced women (table I). It is impossible to state whether those living away from home had more opportunities for sexual activity, or whether the start of sexual activity led to the change in domicile. Within the sexually active group there was an age difference in domicile: younger women were more likely to be living in the parental home or college and older women to be living alone in rented accommodation or cohabiting $(11 \%)$. The virgins were more likely to live in the parental home or college irrespective of age. Only half of them $(54 \%)$ had a boyfriend and they tended to have had shorter relationships. Only $12 \%$ had had a relationship for a year or more, compared with $35 \%$ of the sexually experienced women. Of those who had partners, $87 \%$ chose students in higher education. This contrasts with the sexually experienced women, whose partners were often $(45 \%)$ employed outside the university.

TABLE I-Percentage of women living in various types of accommodation according to sexual experience

\begin{tabular}{|c|c|c|c|c|c|}
\hline & $\begin{array}{l}\text { No. of } \\
\text { women }\end{array}$ & College & Home & Flat & Cohabiting \\
\hline $\begin{array}{l}\text { Virgins } \ldots \\
\text { Sexually experienced }\end{array}$ & $\begin{array}{r}68 \\
268\end{array}$ & $\begin{array}{l}34 \\
22\end{array}$ & $\begin{array}{l}49 \\
33\end{array}$ & $\begin{array}{l}17 \\
34\end{array}$ & $\begin{array}{r}0 \\
11\end{array}$ \\
\hline
\end{tabular}

\section{FACTORS RELATING TO UNPLANNED PREGNANCY}

The sexually experienced women were divided according to whether they were pregnant (51) or not (217). These two groups could not be differentiated by the sociological factors studied. The former were not more likely to come from homes broken by death or separation, nor were they more likely to believe that they had been unwanted children. They did not differ in either academic aspiration or academic achievement, although the pregnant women rated their achievement lower than their marks warranted. The pregnant women were not more likely to have started intercourse at an earlier age, though they were slightly more likely to have had intercourse with only one man than the women who were not pregnant. The factors that differentiated them were related to contraception.

\section{Contraception}

To avoid conception a reliable contraceptive method must be used correctly and consistently, and so the contraceptive techniques were classified as adequate, unreliable, or intermittent. Contraception was adequate when intercourse was always protected by a condom, diaphragm with spermicide, intrauterine contraceptive device (IUCD), or oral contraceptive; $49 \%$ of all sexually active women used adequate contraception. Seventeen per cent of the sexually active women used unreliable methods: rhythm methods (those requiring the determination or estimation of physiological rhythmic periods of infertility), coitus interruptus, chemical spermicides alone, or no form of contraception. Intermittent contraception was practised by $38 \%$ of the sexually active women. They alternated between using reliable and unreliable methods. Table II shows methods of contraception ever used by non-pregnant and pregnant women, and those used by the pregnant women at the probable time of conception. The pregnant women were twice as likely to have used spermicides or withdrawal or rhythm methods and three times as likely to have ever had completely unprotected intercourse. Since the rhythm method was so common among the pregnant women the regularity of their menstrual cycles was examined. The differences between their longest and shortest menstrual cycles were compared with those of a sample, matched for age, attending for contraceptive advice for the first time. According to a $t$ test $^{7}$ the pregnant group showed significantly more variable cycles.

TABLE II-Contraceptive methods used by pregnant and non-pregnant women. Results are percentages*

\begin{tabular}{l|r|r|r|r|r|r|r|r}
\hline & $\begin{array}{c}\text { No of } \\
\text { women }\end{array}$ & $\begin{array}{c}\text { Oral } \\
\text { contra- } \\
\text { ceptives }\end{array}$ & IUCD & $\begin{array}{c}\text { Con- } \\
\text { dom }\end{array}$ & $\begin{array}{c}\text { Spermi- } \\
\text { cide }\end{array}$ & Rhythm & $\begin{array}{c}\text { With- } \\
\text { drawal }\end{array}$ & Nothing \\
\hline $\begin{array}{c}\text { Non-pregnant } \\
\text { women }\end{array}$ & 219 & 57 & 2 & 49 & 11 & 29 & 27 & 9 \\
$\begin{array}{c}\text { Pregnant women: } \\
\begin{array}{c}\text { Used at any time } \\
\text { Used at time of } \\
\text { contraception }\end{array}\end{array}$ & 51 & 29 & 0 & 53 & 20 & 78 & 55 & 29 \\
\end{tabular}

* Percentages are of total number in each group who have ever used a particular method and hence do not total $100 \%$.

The women were asked a series of questions on their contraceptive use. Women in the faculty of science were more likely to reject oral contraceptives than those in other faculties because they were worried about biochemical side effects. Faculty was not related to the classification of contraceptive technique, indicating that another safe method was chosen by many of those who rejected oral contraception.

The women's religiosity had little effect on contraceptive technique. Only $2.3 \%$ of the sexually experienced women who were not pregnant admitted to having religious scruples about contraception. Neither religious denomination nor current religious devotion were associated with overall adequacy of contraceptive technique. Denomination was associated with some attitudes towards particular methods. Of nonpregnant sexually experienced women $20 \%$ thought oral contraceptives were a health hazard, but only $12 \%$ of that group were deterred from using them. Though Roman Catholics were no more likely to believe oral contraceptives to be hazardous, those who did were more likely to be deterred.

Several variables measured the women's opportunities to become aware of the need for contraception and to learn about the techniques. These were: age of first intercourse, number of sexual partners, length of current relationship, unwanted pregnancies among relatives or close friends, previous unwanted pregnancy, and faculty of enrolment. Only the length of current relationship and previous unwanted pregnancy were associated with contraceptive technique. The longer the relationship the greater the proportion of women with good technique. Safe contraceptive technique may be a prerequisite for a lengthy relationship without an unwanted pregnancy. It is also possible that the longer relationships were qualitatively different. Those who did not intend a relationship to last may not have been as concerned about contraception. Women who had previously had an unwanted pregnancy were likely to be in the "intermittent" contraceptive category: an initial period of poor technique was followed by a change to safer methods. This change was not always lasting: three of the pregnant women had previously had an unplanned pregnancy. Among the sexually experienced women in the random sample $10 \%$ had had an unplanned pregnancy.

The position within the family was significantly associated with contraceptive technique. Eldest and last-born children were more likely to have an adequate technique than intermediate children, irrespective of family size. This effect was not apparently mediated by more parental discussion of contraception. Only $27 \%$ of the sexually experienced women had discussed their practices with their parents, though $74 \%$ inferred that their parents would approve. Parental discussion of contraception and knowledge of their daughters' sexual activity were strongly associated with good contraceptive technique.

\section{Discussion}

The sociological data indicated that over the age of 19 most women would be experiencing intercourse within a stable monogamous relationship. Both the proportion of women experiencing intercourse and the proportion of sexually active women who used contraceptives were greater than those found in Britain ${ }^{1}$ and America. ${ }^{2}$ This may be due to cultural differences between the countries or it may be the consequence of changing behaviour patterns. Those with strong religious upbringing or affiliation start intercourse later but then use contraceptives 
independent of religious factors. Those living away from home are more likely to be sexually active.

Any pregnancy results from a complex interaction of psychological, physiological, and sociological causes. Nevertheless, many workers ${ }^{6}{ }^{8}{ }^{9}$ contend that unconscious motivations play a major part in determining who will conceive. The model of Sandberg and Jacobs ${ }^{8}$ lists 14 possible categories of motive for contraceptive rejection. The case histories of pregnant women in our series were classified according to this model. Of the 14 motives only six-denial, shame and embarrassment, fear and anxiety, "coital gamesmanship," sexual identity conflicts, and iatrogenesis-could be detected, and these factors were present in $28 \%$ of the pregnant women. Similar histories were not obtained from controls, so a comparison could not be made.

Iatrogenesis was a factor in six $(12 \%)$ pregnancies. These women were advised to cease oral contraception on medical grounds, but they were not offered any alternative safe method of contraception. Presumably their doctors thought these women would be contraceptively sophisticated because they were sexually active. This was clearly not the case. Benedek ${ }^{9}$ and Raphael $^{6}$ suggest that almost all unplanned pregnancies are unconsciously contrived to satisfy emotional needs. This hypothesis assumes that contraceptives are readily available and that their use is fully understood. Furthermore, manipulative behaviour is often cited as causal when it may be secondary. Although some cases of unwanted pregnancy in our series seemed to provide opportunities for manipulation this does not necessarily mean that pregnancy was incurred for these reasons. A woman finding herself pregnant may then exploit her condition, but she need not have conceived in order to do this.

Only seven women $(14 \%)$ used no contraception at all at the probable time of conception, though in other studies ${ }^{2} 111^{12}$ this figure ranged from $45 \%$ to $65 \%$. The immediate determinants of pregnancy were inadequate contraception technique and less regular menstrual cycles. The pregnant women had significantly more variable cycles than a matched sample of non-pregnant women. This would make prediction of ovulation difficult, yet $63 \%$ of this group relied on a rhythm method at the time of conception. Irregularity of menstruation may be a physiological factor involved in unplanned conception among users. Episodic sexual activity among these women led many to stop oral contraception at the end of one affair and to be unprepared for further sexual intercourse. When the opportunity for intercourse arose they did not ignore the need for contraception, but used those methods at hand-the natural methods.

Two other factors may increase the risk of pregnancy. Firstly, an unreliable method may be recognised as such, but after it has been successfully used, doubts may be allayed. Secondly, when sexually aroused the couple may take a risk they believe to be small.

Most pregnancies among those using natural methods were user failures but there were four method failures. These occurred during the "safe" period as calculated by one of us (JBC) according to Ogino's method. ${ }^{13}$ The use of two recent variants of the rhythm method, the temperature method and Billings's ${ }^{14}$ ovulation method, were rare. One woman conceived while using the temperature method. Two became pregnant while using Billings's method; the failure of contraception was due to the user in one case and the method in the other. The remaining 25 pregnancies among women using a rhythm method were user failures of Ogino's method. The most common errors were: failure to allow for variation in the menstrual cycle; calculating the safe period by counting from the beginning of the last menstruation instead of backwards from the expected date of the next period, and failure to allow at least a five-day sperm survival time. The need to calculate ovulation from an event which had not yet occurred seemed to cause great confusion.

These women derived their information from a variety of sources, including parents-usually the mother-women's magazines, university lectures, and even physiology textbooks. These either do not provide complete and accurate details or else present it so that it can be misunderstood. Many of those using coitus interruptus or chemical spermicides alone were unaware of the hazards of these methods. Few people in this age group know that a man can ejaculate small amounts of semen, sufficient to cause pregnancy, without knowing. Young women using spermicides may have been misled by the manufacturers' assertions that the spermicide alone is as reliable as the diaphragm or condom.

These women students were aware of the need for contraception and had attempted to learn about contraceptive methods. Many pregnancies would not have occurred had the sources consulted provided adequate, clear, and reliable information. Inaccurate or nonexistent information from parents indicated the need to educate not only adolescents but the whole community. Though contraception was widespread there was little appreciation of the relative safety of the various methods. Awareness of the normal variation in the time of ovulation is crucial for those who choose rhythm method. An important factor contributing to the use of unreliable methods was unpreparedness for intercourse.

We thank Mr J S Poliness for his invaluable help with the computer analysis.

\section{References}

McCance, C, and Hall, D J, British Medical fournal, 1972, 2, 694.

2 Bauman, K E, American fournal of Obstetrics and Gynecology, 1970, 108, 203.

3 Giel, R, and Kidd, C, British fournal of Psychiatry, 1965, 111, 591.

${ }^{4}$ Greenberg, N H, Loesch, J G, and Lakin, M, Psychosomatic Medicine, 1959, 21, 297.

5 Olley, P, Seminars in Psychiatry, 1970, 2, 3.

${ }^{6}$ Raphael, B, Medical fournal of Australia, 1972, 2, 35.

7 Ferguson, G A, Statistical Analysis in Psychology and Education, 2nd edn. New York, McGraw Hill, 1966.

${ }^{8}$ Sandberg, E C, and Jacobs, R I, American fournal of Obstetrics and Gynecology, 1971, 110, 227.

${ }^{9}$ Benedek, T, Parenthooa: Its Psychology and Psychopathology. Boston, Little, Brown, and Co, 1970

10 Flapan, M, American fournal of Orthopsychiatry, 1969, 39, 402.

${ }^{11}$ Amdur, S B, and Oreschnik, R W, Fournal of the American College Health Association, 1972, 21, 149.

12 Diggory, P, Lancet, 1969, 1, 873.

13 Ogino, K, Zentralblatt für Gynäkologie, 1931, 56, 721.

14 Billings, J, Ovulation Method. Melbourne, Advocate Press, 1964.

$A$ patient eats a small quantity of dried yeast every morning. Is there likely to be any danger to health?

Dried yeast consists of unicellular fungi and includes among its constituents thiamine, nicotinic acid, riboflavine, pyridoxine, folic acid, vitamin $B_{12}$, inositol, proteins, carbohydrates, and enzymes. A small dose (6-8 $\mathrm{g}$ in adults) may be used as a dietary supplement particularly for the vitamin B group and is harmless. At high doses gastrointestinal upsets such as diarrhoea occur.

Is it safe to mix morphine $(1.5 \mathrm{mg}$ ) and prochlorperazine mesylate (Stemetil) (12.5 mg) in the same syringe for intravenous administration to a patient with acute myocardial infarction?

The uncomplicated answer is no. Even when administered separately, both morphine and prochlorperazine mesylate (Stemetil) -a phenothiazine-may have profound cardiovascular effects in a patient with acute myocardial infarction. Furthermore, prochlorperazine enhances the effect of morphine. In principle the mixing of different drugs in the same syringe is highly undesirable and should be discouraged. Prochlorperazine is incompatible with numerous drugs and in clinical practice should be administered separately. With these reservations in mind it must be conceded that prochlorperazine edisylate (Compazine-USA) is reported to be compatible with morphine sulphate. A proprietary combined preparation containing morphine tartrate $15 \mathrm{mg}$ and an alternative phenothiazine-cyclizine tartrate $50 \mathrm{mg}$ (Cyclimorph)-is available. 